Volume 10, Issue 6, November-December 2019, pp. 254-260, Article ID: IJM_10_06_025

Available online at http://iaeme.com/Home/issue/IJM?Volume $=10 \&$ Issue $=6$

Journal Impact Factor (2019): 9.6780 (Calculated by GISI) www.jifactor.com ISSN Print: 0976-6502 and ISSN Online: 0976-6510

\title{
PERFORMANCE OF NPA OF NON-PRIORITY AND PRIORITY SECTOR OF PUBLIC SECTORS BANKS IN INDIA
}

\author{
Dr. C. Ganesan \\ Professor, Department of Commerce, VELS Institute of Science, \\ Technology and Advanced Studies, Chennai, Tamilnadu, India
}

\section{Dr. M. NirmalDev}

Associate Professor, Department of Commerce, VELS Institute of Science, Technology and Advanced Studies, Chennai, Tamilnadu, India

\section{J. Sherli}

Assistant Professor, Department of Commerce, VELS Institute of Science, Technology and Advanced Studies, Chennai, Tamilnadu, India

\begin{abstract}
Priority sector lending or PSL had been forecasted. So that these sectors get institutional loans from PSL were segments are difficult to getting credit. The sector concerning institutions of financial are referred to as Non-Priority Sector lending and the credit is lending readily. These sectors are exciting until now. Each and every time the money is attracted and entire enduring sectors other than PSL are covered by these divisions. This article considers the part of the NPA of the sector which concerns institutions of financial and the Priority sector in the whole PSB of NPA in India. The near research examined both the inclinations in sector-wise NPAs of PBS and the significant influence of NPA of the sector which concerns institutions of financial and the priority sector over the entire NPAs of PSBs. And also, the achievement of disgusting advances over total NPAs of PSBs is discovered. The secondary data is considered in this research. The period of the research is 12 years i.e., from 2007 to 2018. The tools such as correlation, ratios, Regression, $t$-test had been employed to analyze the statics have been tattered for these analyses.
\end{abstract}

Keywords: Public Sector Automotive industry, NPA, Priority sector Advances, NonPriority Sector.

Cite this Article: Dr. C. Ganesan, Dr. M. NirmalDev and J. Sherli, Performance of NPA of Non-Priority and Priority Sector of Public Sectors Banks in India, International Journal of Management (IJM), 10 (6), 2019, pp. . 254-260.

http://iaeme.com/Home/issue/IJM?Volume $=10 \&$ Issue $=6$ 


\section{INTRODUCTION}

The automotive industry system is acted towards as an essential part of the progress of a nation's economy. The presentation of the economies had been associated directly and unconditionally towards the performance of the automotive industry. The key stakeholders in the development of the economy are the commercial automotive industry. The incidence of NPAs has become a serious hazard to the division of the automotive industry.

In common, borrowers repay the dues by their personal due dates to the automotive industry. However, some turn obstinate. This is because of the inability and unwillingness of borrowers to repay. If such liability is presented as a common liability and interest is accumulated over such liability as an ordinary profit, then the balance sheet had been displaying an improper depiction of the financial position of the automotive industry. Therefore, strict necessities have been laying by RBI regarding the credit of NPA.

As per RBI, an NPA is a lend or advances where:

1. Liability - the rate of interest and/or installment of capital amount leftovers late for exceeding 90 days.

2. CC or Overdraft - account is out of commission

ie

a) dazzling sense of balance leftovers uninterruptedly in superfluous of the withdrawing power or limits sanctioned, or

b) The remaining balance is within the limits sanctioned or power of withdrawing, then there are no continuous credits for 90 days as over the balance sheet date, or the credits are inadequate to cover the debited interest throughout the same time period.

3. The purchase and discount of the bill -invoice leftovers late for exceeding 90 days.

4. Short term crops (season of the crop is up to a single year) - installment of capital or the borrowed money leftovers late for seasons of two crop.

5. Long term crops - installment of capital or the borrowed money leftovers late for season of the crop.

\subsection{Priority Sector Lending}

The PSL is projected to offer institutional investors to those divisions and sections for which it is not easy to borrow credit. As per the standards of the priority division, the scheduled retail automotive industry had to provide $40 \%$ of them lends (estimated regarding ANBC) to the recognized priority divisions through the instructions of RBI. The procedures are reviewed irregularly through setting limits for subsectors and other qualifications for the recipient groups. If these targets are not achieved, automotive industry has to finance the building programs implemented by the government for the anxious sectors.

\subsection{Categories under Priority Sector}

- Farming

- Small sized entities of MSME

- Export Credit

- Learning

- affordable housing

- Growth of a Social Infrastructure

- sustainable energy

- others 
Moreover, domestic automotive industry had been focused to promise that the global loaning to non-firm agrarian does not go down under the systematic regular of the past three years recital. All hard work should be directed to get to the grade of 13.5 per hundred through lending's to the recipients who established the direct farming industry earlier. The valid systematic average outline for compute performance under PSL will be circulated each and every single year. The relevant system-wide standard value had been attained as 11.57 percent for 2017-16 of FY. The sector concerning institutions of financial are referred to as Non-Priority Sector lending and the credit is lending readily These sectors are exciting until now. Each and every time the money is attracted.

\section{ANALYSIS OF LITERATURE}

Kohli's (1997) reveals that in spite of the fact that going to credit a program for PSL is influential in India.it is required to hold up to small-scale industries.

Uppal's (2011) presumes that the priority sector advance of all the banking groups is increasing. Regardless of raising advance, Indian automotive industry does not achieve target approximately fixed through Indian automotive industry had been opposing numerous harms like transaction cost, high NPAs, low profitable, and so on because of the PSL. It is obligatory to discover the answers for these issues otherwise growth of the Indian automotive industry will stop.

Jaynal Ud-din Ahmed's (2012) shows that the recovery state in agriculture and connected behavior in contrast to other urgency sectors is hopeless in three districts under thought. There is an improvement in the volume of NPAs through the rise of PSL. However, it cannot argue that PSL is the only factor in magnifying the size of NPAs in the area under research, other factors like ratio of credit-deposit, the ratio of NPA to advance, the ratio of capital adequacy are responsible correspondingly for improved NPAs.

Dr. G Nagarajan., N. Sathyanarayana, Ali Asif, (2015) deliberate the relationship among NPA and recovery. Researchers found that the main reason for the NPA is writing off faulty loans and bad loans are superior in the case of PSL in comparison to Non-PSL.

ShabbirNajmi, MujooRachna, (2015) deliberate the relationship among public and private automotive industry NPA. The author deduced that the public automotive industry' NPA is higher than the private-sector automotive industry because the PSL of public is higher when compared to the private automotive industry.

\subsection{Objectives of the Proposal}

- To examine the inclinations in the NPA of the sector which concerns institutions of financial and priority sectors of PSB.

- To discover the major association among the NPA of Priority Sector and entire NPAs of PSB.

- To discover the major association among the NPA of the sector which concerns institutions of financial and the entire NPAs of PSB.

- To discover the influence of the gross advances over the entire NPAs of PSB throughout the research period.

\subsection{HYPOTHESIS}

- Ho1: There is no major association among the entire NPAs and the NPA of Priority Sector.

- Ho2: There is no major association among the entire NPAs and the NPA of the sector which concerns institutions of financial.

- Ho3: There is no major dissimilarity in the size of the influence of Gross Advances over the entire NPAs. 


\section{RESEARCH METHODOLOGY}

The existing research had been directing over the data which is gathered by non-users. These are collected from the RBI website for a duration of 12 years, i.e., between 2007 and 2018. the package of SPSS had been employed to examine the tools such as correlation, ratios, Regression, t-test which are employed to examine the statics.

\subsection{Data Analysis and Interpretation}

Table 1: Priority and Non-Priority Sectors NPAs in Public Sector Automotive Industry in India

\begin{tabular}{|c|c|c|c|c|c|c|c|}
\hline YEAR & $\begin{array}{l}\text { PRIORITY } \\
\text { SECTOR }\end{array}$ & $\%$ & $\begin{array}{l}\text { NON-PRI } \\
\text { SECTOR }\end{array}$ & IITY & $\%$ & $\%$ & TOTAL \\
\hline 2008 & 222.36 & 53.75 & 182.79 & 44.18 & 8.55 & 2.07 & 413.70 \\
\hline 2009 & 225.19 & 57.96 & 156.03 & 40.16 & 7.32 & 1.88 & 388.54 \\
\hline 2010 & 248.74 & 61.48 & 150.07 & 37.10 & 5.74 & 1.42 & 404.56 \\
\hline 2011 & 242.01 & 53.75 & 205.28 & 45.59 & 2.97 & 0.66 & 450.26 \\
\hline 2012 & 304.96 & 50.89 & 291.14 & 48.58 & 3.14 & 0.52 & 599.24 \\
\hline 2013 & 401.86 & 53.82 & 342.35 & 45.85 & 2.43 & 0.32 & 746.64 \\
\hline 2014 & 557.80 & 47.57 & 588.26 & 50.17 & 26.56 & 2.27 & 1172.62 \\
\hline 2015 & 672.76 & 40.91 & 960.31 & 58.39 & 11.55 & 0.70 & 1644.61 \\
\hline 2016 & 798.99 & 35.16 & 1472.35 & 64.79 & 1.30 & 0.06 & 2272.64 \\
\hline 2017 & 966.11 & 34.69 & 1815.98 & 65.21 & 2.59 & 0.09 & 2784.68 \\
\hline 2018 & 1258.09 & 23.30 & 4141.48 & 76.70 & 34.82 & 0.64 & 5399.57 \\
\hline
\end{tabular}

\subsection{Objective: 1}

This table exposes the NPA in sector-wise of PSB for 12 years among 2007 and 2018. It describes that the percentage of the NPA of priority sector is greater when compared to previous among 2007 of FY and 2013 of FY and viewed as a fall in 2014 of FY and it is fixed to go down till 2018 of FY. In the case of NPA of the sector which concerns institutions of financial, it is continued to fall between 2007 of FY and 2011 and it was detected as stable between 2011 of FY and 2013 of FY and from 2013 of FY it sustained to rise significantly between 45.85 in 2013 of FY and 76.7 in 2018 of FY.

\subsection{Objective: 2}

- Ho1: There is no major association among the entire NPAs and the NPA of Priority Sector.

- H11: There is a major association among the entire NPAs and the NPA of Priority Sector.

The association among the NPA of Priority Sector and entire NPAs had been discovered as 0.963. These specify a higher degree of a positive association among the entire NPAs and the NPA of Priority Sector. The mean variances among the two variables had been attained as 1164.834, and the estimated value of t-test had been attained as -2.637 . The p-value had been attained as 0.023 where $\mathrm{p}$ is smaller than 0.05 . Later the $\mathrm{H} 0$ or null hypothesis had been excluded. This result proves a strong association among the two variables. As a result, here is a rise in both the entire NPAs. And the NPA of the priority sector. 


\subsection{Objective: 3}

- Ho2: There is no major association among the NPA of the sector which concerns institutions of financial and the entire NPAs

- H12: There is an important association among the entire NPAs and the NPA of the sector which concerns institutions of financial.

The correlation among the entire NPAs and the NPA of the sector which concerns institutions of financial had been discovered as 0.997 from the statistical test. These specify a higher degree of optimistic association among the entire NPAs and sector which concerns institutions of financial. The mean variances among the two variables had been attained as 516.0248 and the estimated values of t-test had been attained as -5.169 , and the $p$-value had been attained as 0.000 where $\mathrm{p}$ is smaller than 0.05 . Later $\mathrm{H} 0$ or null hypothesis had been excluded. There is a stable association among the two variables. As a result, there is a rising in both the entire NPAs and the NPA of the sector which concerns institutions of financial.

\subsection{Objective: 4}

Table 2: Gross Advances and Gross NPAs in Public Sector Automotive Industry in India (Amount In `Billion) As On March 31st

\begin{tabular}{|l|l|l|l|}
\hline YEAR & $\begin{array}{l}\text { GROSS } \\
\text { ADVANCE }\end{array}$ & GROSS NPAs & $\begin{array}{l}\text { GROSS NPAs to } \\
\text { GROSS } \\
\text { ADVANCE (\%) }\end{array}$ \\
\hline 2007 & 8778.25 & 476.22 & 5.5 \\
2008 & 11347.24 & 413.7 & 3.6 \\
2009 & 14644.93 & 388.54 & 2.7 \\
2010 & 18190.74 & 404.56 & 2.2 \\
2011 & 22834.58 & 450.26 & 2 \\
2012 & 27334.58 & 599.24 & 2.2 \\
2013 & 30798.04 & 746.64 & 2.4 \\
2014 & 35503.89 & 1172.62 & 3.3 \\
2015 & 45601.69 & 1644.61 & 3.6 \\
2016 & 52159.2 & 2272.64 & 4.4 \\
2017 & 56167.18 & 2784.68 & 5.0 \\
2018 & 58183.48 & 5399.57 & 9.3 \\
\hline
\end{tabular}

- Ho3: There is no major difference in the size of the force of Gross Advances over the entire NPAs.

- H13: There is a major dissimilarity in the size of the influence of gross advances over the entire NPAs.

The numerical test results of association among the entire NPA and Gross Advances had been attained as 0.841 . These specify a higher degree of a positive association among the entire NPA and Gross Advances. As a result, there is a rise in both gross advances and the entire NPAs.

The adj R2 had been attained as 0.679 from the regression test. These specify the weakening model which predicts the dependent variable of entire NPA had been described through $68 \%$ of the gross advances and enduring had been described through other factors. Here $\mathrm{p}$ is not 
greater than 0.05 . These specify the overall regression model based on statistics significantly and forecasts the entire NPAs. Here the $\mathrm{H} 0$ or null hypothesis had been rejected. So that there is no dissimilarity of size in the size of the influence of gross advances over the entire NPAs of PSBs.The regression equation had been expressed as entire NPAs which is equal to $-866.637+$ .071(Gross Advances).

\section{FINDINGS}

- The NPA of priority sector of PSB had been raised among Rs 215.36 of billion at the ending of 2007 March and Rs 1258.09 of billion at the ending of 2018 March. The percentages of NPA of the Priority sector of PSB had been declined from 2014.

- The NPA of the sector concerning institutions of financial of PSB had been raised among Rs 254.94 of billion at the ending of 2007 March and Rs 4141.48 of billion at the ending of 2018 March. The percentages of NPA of the Priority sector of PSB had been superior since 2014 when compared to the previous year.

- There is a definite association among the NPA of entire and the Priority Sector and a strong relationship among the NPA of entire and sector which concerns institutions of financial.

- Both the NPA of non-Priority and Priority Sector are fundamental entire NPAs of PSB.

- A positive association among the entire NPA and Gross Advances and these are crash considerably over the entire NPAs of PSBs.

\section{CONCLUSION}

The major key issue for the system of banking in India is the NPA. The giving of the division of priority, NPAs are higher than 50\% in entire NPAs until the year 2013. After that, this was declined progressively. NPA of the sector which concerns institutions of financial hovers $50 \%$ approximately after the year 2013.NPA of sector which concerns institutions of financial is raised progressively throughout the period. Through the perceptions of these researches, both the NPA of the sector which concerns institutions of financial and priority sectors display the significant influences over entire NPAs of PSB. But the contribution of NPA of the sector which concerns institutions of financial had been discovered as higher when compared to NPA of the priority sector of entire NPAs. As a result, the gross advances contain a significant influence over the entire NPAs of Indian PSB. In a shorter period, falling whole NPAs is difficult for automotive industry. Therefore, automotive industry should recognize which category contributes NPAs under non-priority and priority sectors which concern entire NPAs. Hence, the government and automotive industry should take efforts to reduce the NPA in sector-wise.

\section{REFERENCES}

[1] Master Circular -Prudential norms on Income Recognition, Asset Classification and provisioning pertaining to Advances, 2017.

[2] R K Uppal "Priority sector advances Trends, issues and strategy", Journal of Accounting and Taxation, 1(5), 2011, pp 89.

[3] R.Shenbagavalli, S.Senthilkumar and Dr.T.Ramachandran, A Strategy to Manage the Npas of Public Sector Banks, International Journal of Management (IJM), Volume 4, Issue 3, May- June (2013) 
[4] N. Goyal, R. Agrawal, and Agrawal, "A study of the effect of priority sector lending (sectorwise) on Non-Performing Assets of India commercial automotive industry," International Journal of Research in Finance and Marketing, 5(5), 2017, pp 85.

[5] D.Nagarajan, Sathyanarayan, and A. A. Ali, "Non-Performing Asset is a threat to India Banking Sector- A comparative study between priority and non-priority sector lending in public sector automotive industry", International Journal of Advanced Research in Management and Social Sciences, 2(11), 2015, pp 39.

[6] Dr. V. Antony Joe Raja and V. Vijayakumar, A Study on Stress Management among the Different Type of Working Employees of Banking Sector with Skill Development Orientation Solution in India. International Journal of Marketing and Human Resource Management, 8(1), 2017, pp. 13-17.

[7] B. Pandya, "Impact of priority sector advances on bank profitability: Evidence from

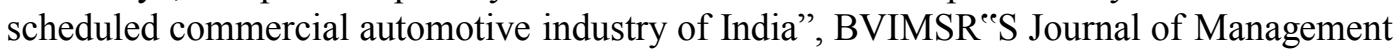
Research, 7(2), 2017, pp 75.

[8] Dr. C. Mahadeva Murthy and Prof. S.N. Pathi, An Assessment of Risk Management in Banking Sector: A Study with Special Reference to Public and Private Sector Banks in India, International Journal of Advanced Research in Management (IJARM), Volume 4, Issue 3, September - December 2013 